\title{
PROGRESSIVE MUSCULAR DYSTROPHY OF THE EXTRA-OCULAR MUSCLES IN A NEGRO*
}

\author{
BY \\ D. SEVEL $\uparrow$ \\ St. John Eye Hospital
}

ABOUT 150 cases of progressive muscular dystrophy involving the extra-ocular muscles have so far been recorded in the literature. As far as can be ascertained, this condition has never been described in a Negro.

The myopathies are characterized by a primary dystrophy of voluntary muscle. Kiloh and Nevin (1951) reviewed the problem of progressive dystrophy of the external ocular muscles and concluded that the pathology directly affected the muscles and was not due to a degeneration of the oculomotor nuclei. They reported that a family history of the condition may be obtained in about half the cases.

Progressive muscular dystrophy usually begins with a progressive ptosis; later the movements of the extra-ocular voluntary muscles become restricted, resulting in a partial or complete external ophthalmoplegia. These manifestations are usually bilateral and symmetrical. When the ophthalmoplegia is complete the ocular axes are divergent, and the ocular movements are equally restricted in all fields of gaze in both eyes. Although the disease is slowly progressive, it may spontaneously regress at any stage.

In 25 per cent. of cases the orbicularis oculi muscles show weakness which may progress to complete paralysis (Nevin and Kiloh, 1958). 10 per cent. of cases also show evidence of weakness of the muscles of the face, neck, and shoulder girdle (Nevin and Kiloh, 1958; Teasdall and Sears, 1960), the facial weakness being always more marked in the orbicularis oculi. Hyperthyroidism, premature baldness, testicular atrophy, and cataracts have all been described as possible associated features of the condition (Teasdall and Sears, 1960).

The intra-ocular muscles are not usually involved in the condition-the pupils are equal and react to light directly, consensually, and to accommodation.

Microscopic examination reveals muscle fibre degeneration of a non-specific nature, with a marked increase in fibrous and collagen tissue. There is also an increased number of sarcolemmal nuclei.

\section{Case Report}

A 20-year-old Bantu male presented at the St. John Ophthalmic Hospital complaining of ptosis. There was no family history of the condition, which had started insidiously at the age of 3 years on the left side, and had progressed to a bilateral ptosis, followed by paralysis of the extra-ocular muscles. The facies showed the typical sleepy expression; the forehead was constantly wrinkled

* Received for publication June 19, 1963

† Present address: Oxford Eye Hospital. 
in an effort to elevate the lids, the eyebrows were elevated well above the supra-orbital ridges, and the head was tilted backwards (Fig. 1.)

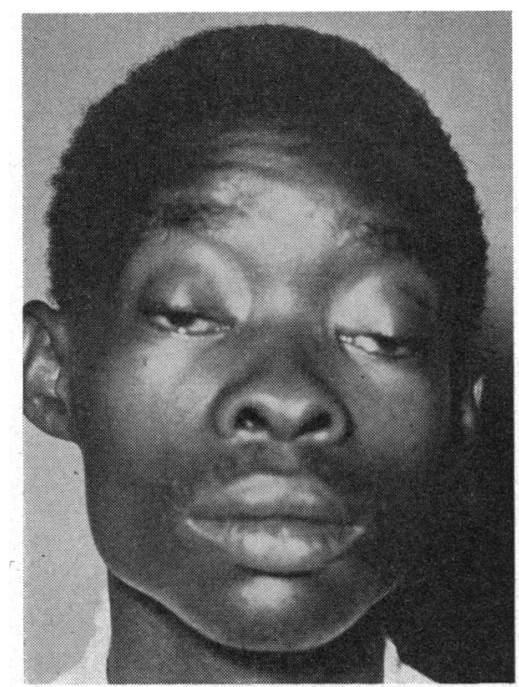

Fig. 1.-Progressive muscular dystrophy of the extra-ocular muscles in a Negro aged 20.

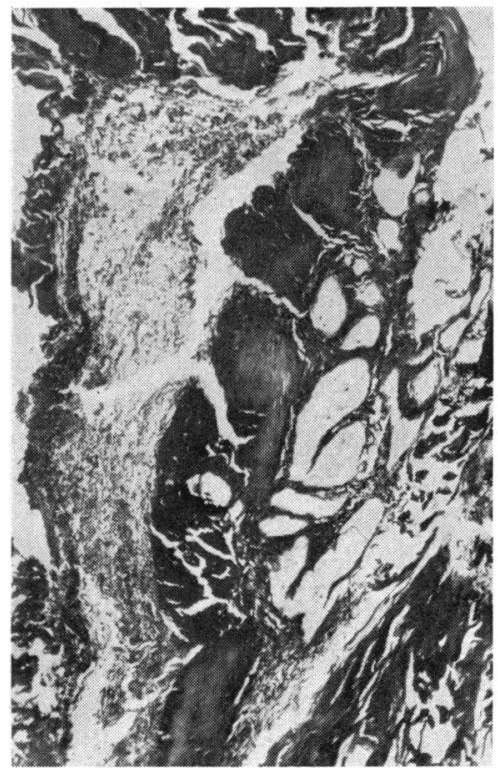

Fig. 2.-Section of the lateral rectus muscle showing fibrous connective tissue and fatty connective tissue in which a few atrophic muscle fibres can be identified. There is no evidence of inflammatory cell infiltration. $\times 60$.

Examination.-Complete external ophthalmoplegia was associated with bilateral ptosis. The palpebral fissures were $4 \mathrm{~mm}$. in width and did not widen. There was no diplopia. The orbicularis oculi muscles were weak, but closure of the lids was just possible; there was compensatory overaction of the frontalis muscle. The remaining facial muscles and the rest of the ocular examination were normal.

The shoulder girdle muscles and posterior cervical muscles showed no wasting or loss of power (Kiloh and Nevin, 1951). Speech was normal and there was no evidence of bulbar weakness (Teasdall and Sears, 1960). The pupillary reactions were normal. The Wassermann reaction was negative (Kiloh and Nevin, 1951).

The patient was transferred to the Neuro-surgery Department of Baragwanath Hospital, for investigation.

A general neurological examination, $x$ ray of the skull, carotid and vertebral angiography and air studies revealed no disease of the central nervous system.

On January 5, 1961, a biopsy was taken of the left orbicularis and left lateral rectus muscles. The patient refused to allow a biopsy of the skeletal muscle of the shoulder girdle (McAuley, 1956).

Microscopic Examination.-This revealed muscle fibre degeneration and loss of muscle striation with increase of fibrous tissue and fat. There was vacuolar and hyaline degeneration of the sarcoplasm, and proliferation of the sarcolemmal nuclei. Many bundles of nerve fibres were present and showed no evidence of degeneration (Fig. 2).

Treatment.-As there was complete external ophthalmoplegia and paralysis of the orbicularis oculi muscles, there was a danger of exposure keratitis if the ptosis was corrected. The patient had adjusted himself to the disability, and it was decided not to correct the ptosis by operative measures, but ptosis props were recommended. 


\section{Discussion}

An interesting feature of this case is the early onset of the condition; most of the other cases described commenced at a much later age.

\section{Summary}

The case is described of a Negro aged 20, who showed progressive muscular dystrophy of the extra-ocular muscles.

\section{REFERENCES}

KILOH, L. G., and NeviN, S. (1951). Brain, 74, 115.

MCAULEY, F. D. (1956). Brit. J. Ophthal., 40, 686.

NeviN, S., and KILOH, L. G. (1958). In "Systemic Ophthalmology", ed. A. Sorsby, 2nd ed., p. 369, Butterworth, London.

Teasdall, R. D., and Sears, M. L. (1960). A.M.A. Arch. Neurol., $2,281$.

\section{ADDITIONAL BIBLIOGRAPHY}

JAMPOLSKY, A., TAMLER, E., and MARG, E. (1959). A.MA. Arch. Ophthal., 61, 402.

Nicolaissen, B., and Brodal, A. (1959). Ibid., 61, 202. 